\title{
Malnutrition and Associated Factors among Adult People Living with HIV/AIDS Receiving Antiretroviral Therapy at Organization for Social Service Health Development in Jimma Town Oromia Region South West Ethiopia
}

\author{
Admasu Belay Gizaw ${ }^{1 *}$, Aklilu Eshetu ${ }^{2}$ and Dagmawit Birhanu ${ }^{1}$ \\ ${ }^{1}$ Jimma University Institute of Health School of Nursing and Midwifery, Ethiopia \\ ${ }^{2}$ Kafa Zone Saylem Woreda Health Office, Ethiopia
}

*Corresponding author: Gizaw AB, Jimma University Institute of Health School of Nursing and Midwifery, PO Box: 378, Ethiopia, Tel: +251925270512; Fax: 0471-11-14-50; E-mail: admasu.belay@ju.edu.et

Received date: May 3, 2018; Accepted date: June 30, 2018; Publication date: July 9, 2018

Copyright: $@ 2018$ Gizaw AB, et al. This is an open-access article distributed under the terms of the Creative Commons Attribution License, which permits unrestricted use, distribution and reproduction in any medium, provided the original author and source are credited.

\begin{abstract}
Introduction: Human immunodeficiency virus (HIV) infection is a global pandemic, since its first recognition has caused serious socio-economic problems especially in Sub-Saharan Africa. Due to different reasons HIV and malnutrition are directly or indirectly linked to each other. HIV infection by itself induces malnutrition and reversely malnutrition exacerbates the disease progression. The main goal of this study was to assess the level of malnutrition and its determining factors among adult people living with HIVIAIDS and receiving anti-retroviral therapy.
\end{abstract}

Method: A cross-sectional study was conducted from March 1 to March 30/2017 to assess the level of malnutrition. The study participants were selected using simple random sampling method. A total of 337 participants were included. Descriptive statistics and chi-Square test was done to describe and identify factors associated with malnutrition among people living with Human immunodeficiency virus (HIV).

Result: The study showed that $43 \%$ of the study participants were malnourished. Monthly income, educational status and WHO staging at initiation of antiretroviral therapy were identified as significantly associated with malnutrition in this study.

Conclusion: Malnutrition among patients living with HIV at organization for social service health development was high and the major risk factors for malnutrition was found to be low monthly income, educational status and WHO staging of antiretroviral therapy initiation.

Keywords: Human immunodeficiency virus; Acquired immuno deficiency syndrome; Malnutrition

\section{Introduction}

Globally 36.7 million people were living with HIV/AIDS; among those 34.5 million are adults. Sub-Saharan Africa remains most severely affected, with nearly 1 in every 25 adults people levies with HIV and accounting for nearly two-thirds of the people living with HIV worldwide [1]. According to the Centers for Disease Control and Prevention (CDC), 1.1 million Americans were living with HIV at the end of 2015 and the latest HIV related estimates and projection by Ethiopians public health institutes, Federal Ministry of Health, 2014 the projected adult HIV prevalence since 2015 is $1.1 \%$ (urban $2.3 \%$ and rural $0.5 \%$ ).The report shows that the numbers of people living with HIV and AIDS for the year 2015 are 753,083 [1,2].

Approximately 826 million people in the world are undernourished from those 792 million people in the developing world and 34 million in the developed world. John Mason and colleagues claimed that $32 \%$ of the global disease burden could be removed by eliminating malnutrition [3]. Malnutrition plus HIV causes a serious health risk for the patient as well as critical crises for the globe especially to sub-
Saharan countries like Ethiopia. Nutritional status is strongly predictive of survival and functional status during the course of HIV infection [4,5].The HIV epidemic not only affects the health of individuals, but also impacts households, communities, and the development and economic growth of nations. Many of the countries hardest hit by HIV also suffer from other infectious diseases, food insecurity, and other serious problems [6].Recent evidence indicates that earlier ART will help people with HIV to live longer, healthier lives, and substantially reduce the risk of transmitting HIV to others. The move could avert an additional 3 million deaths and prevent 3.5 million more new HIV infections between now and 2025 [7]. Standard antiretroviral therapy (ART) consists of the combination of antiretroviral (ARV) drugs to maximally suppress the HIV virus and stop the progression of HIV disease.

ART also prevents onward transmission of HIV. Huge reductions have been seen in rates of death and infections when use is made of a potent ARV regimen, particularly in early stages of the disease. WHO recommends ART for all people with HIV as soon as possible after diagnosis without any restrictions of CD4 counts. It also recommends offer of pre-exposure prophylaxis to people at substantial risk of HIV infection as an additional prevention choice as part of comprehensive 
prevention. Countries are now following to adapt and implement these recommendations within their own epidemiological settings [8].

Current antiviral treatments can reduce HIV-associated morbidity, prolong survival, and prevent HIV transmission. Combination antiretroviral therapy (ART) containing preferably three active drugs from two or more classes are required for durable Virologic suppression. Regimen selection is based on virologic efficacy, potential for adverse effects, pill burden and dosing frequency, drug-drug interaction potential, resistance test results, co morbid conditions, social status, and cost even if it's provided for free for developing countries like Ethiopia. With prolonged virologic suppression, improved clinical outcomes, and longer survival, patients will be exposed to antiretroviral agents for decades. Therefore, maximizing the safety and tolerability of ART is a high priority. Emergence of resistance and/or lack of tolerability in individual patients require availability of a range of treatment options [9].

People living with HIV need to protect themselves from opportunistic infections, which are a serious threat to anyone living with HIV. Opportunistic infections (OIs) are infections that are more frequent or more severe because of immune-suppression in HIVinfected persons, and they are the major clinical manifestation of HIV patients [10]. The most common opportunistic diseases in HIV patients are Candida esophagitis, Pneumocystis carinii pneumonia (PCP), Mycobacterium tuberculosis infection, Cytomegalovirus (CMV), Cryptococcus, kaposi sarcoma, herpes zoster and tuberculosis [11]. However, majority of OIs can be averted by the appropriate use of HAART. Based on 2013 UNAIDS country estimates of number of HIV infected children ART was estimated to have potentially averted by approximately 161,000 cases of OIs annually [12].

Currently, most widely available drugs for HAART in Ethiopia were NRTI (Zidovudine, Didanosine, Zalcitabine, Stavudine, Lamivudine, Abacavir, Tenofovir, Emtricitabine, NNRTI (Nevirapine, Delavirdine, Efavirenz, Etravirine, Ripivirine), PI (Saquinavir, Indinavir, Ritonavir Nelfinavir, Amprenavir, Lopinavir, Fosamprenavir, Atazanavir, Tipranavir, Darunavir) and INSTI (Raltegravi, Elvitegarvir, Dolutegravir) [13]. Malnutrition and HIV negatively affect each other. HIV infection results in poor nutrition. HIV is a cause of nutritional deficiencies through its effect on nutrient absorption and decreased intake, HIV itself or Opportunistic infections can result in increased energy expenditure and as a result, malnutrition and HIV coexist in a vicious perpetuating cycle [5].

There is no international agreement regarding assessment of malnutrition in HIV positive adults. Various indices like Body Mass Index (BMI), weight, Mid-upper Arm Circumference (MUAC), skin fold thickness, serum albumin and electrolyte values and Body Cell Mass (BCM) are suggested for nutritional assessment of adults. BCM depletion remains the most important disease marker; which even decreased in asymptomatic HIV patients. Patients with HIV associated wasting irrespective of the underlying cause have a decreased rate of survival independent of other factors [14].HIV causes immune impairment leading to malnutrition which leads to further immune deficiency, and contributes to rapid progression of HIV infection to AIDS. Well-nourished the person is less likely to progress faster to AIDS but the reverse is true for a malnourished person, because his body is weak to fight infection. It has been proved that good nutrition increases resistance to infection and disease, improves energy and thus makes a person stronger and more productive [15]. Wasting syndromes are defined by loss of more than $10 \%$ of the usual body weight with a lack of other detectable cause of wasting other than the
HIV infection itself [16]. Weight loss often is the initiating event in a vicious cycle of increased fatigue and decreased physical activity, including the ability to prepare and consume food [17]

Increased availability of highly active antiretroviral therapy (HAART) in LMICs has led to some improvement of the nutritional status of patients [18]. However, for certain individuals, under nutrition and weight loss persist despite therapy. Just like with HIV, HAART and malnutrition contribute to a deadly cycle. Highly active antiretroviral therapy (HAART) leads to increased requirements for macro and micronutrients, high metabolic demands [19] and low appetite [20], which perpetuate under nutrition [21], simultaneously malnutrition exacerbates side effects [22-25], alters drug pharmacokinetics and impinges on adherence [26]. There by limiting the beneficial effects of the therapy. Malnutrition also was found to increase the rate of complications during hospitalization in other diseases. This generally results in further medical intervention that may include expensive diagnostic and therapeutic measures. The increase in expenditure adds to the overall economic burden of providing health care [27]. In one meta-analysis published in 2015, malnutrition $\left(\mathrm{BMI}<18.5 \mathrm{~kg} / \mathrm{m}^{2}\right)$ was reported as one of the leading causes of hospital admission among HIV positive adults in the Africa region [28].

Weight loss which leads to severe and moderate malnutrition is common in HIV infection and can be caused by low dietary intake due to loss of appetite, mouth ulcers, and food insecurity and also due to mala absorption of macronutrients and an altered metabolism [29].The problem of HIV/AIDS and malnutrition in Ethiopia is so marked that it needs research for better awareness on the nutritional status of HIV positive patients and on the determinants of malnutrition in order to design palliative programs accordingly. The major goal of current study is to determine the level of malnutrition and its determining factors in among HIV positive patients at OSSHD.

\section{Methods and Materials}

\section{Study area and period}

The study was conducted in Jimma Town organization for social service health development (OSSHD) Jimma branch. The Organization Social services and Health Development (OSSHD) of Jimma branch is established in 2003 G.C and the office has been working in alliance with many Governmental and non-governmental organization to realize the national goals of OSSHD in Ethiopia. Currently Organization for Social Services and Health Development (OSSHD) of Jimma branch has been carried out three projects and CDC is one of three. Through this project, there are two major components that are ICT and care and support. There are 2 B.Sc. nurses 3 clinical nurses and one community counselors' staffs working there now. The study was conducted from March 1/3/2017 to March 30/3/2017.

\section{Study design}

An institutional based cross-sectional study design was used.

\section{Population}

\section{Source population}

All HIV positive adults on HAART Jimma branch organization for social services health development (OSSHD) clients. 
Citation: Gizaw AB, Gebremichael AE and Kebede DB (2018) Malnutrition and Associated Factors among Adult People Living with HIVIAIDS Receiving Antiretroviral Therapy at Organization for Social Service Health Development in Jimma Town Oromia Region South West Ethiopia. Gen Med (Los Angeles) 6: 315. doi:10.4172/2327-5146.1000315

Page 3 of 8

\section{Study population}

Sampled HIV positive patients on HAART in Jimma branch organization for social services health development (OSSHD) All children PLHIVs and PLHIVs not started HAART yet were excluded.

\section{Operational definition}

The patient is considered under Malnutrition if BMI score is $<18.5$ $\mathrm{Kg} / \mathrm{m}^{2}$, Moderate malnutrition: BMI $16-18.5 \mathrm{Kg} / \mathrm{m}^{2}$ and severe malnutrition $\mathrm{BMI}<16 \mathrm{Kg} / \mathrm{m}^{2}$.

\section{Sample size and sampling technique:}

The sample size was determined using single population proportion formula taking $50 \%$ prevalence of malnutrition among adults with HIV/AIDS on ART with 5\% marginal error and 95\% confidence interval $(\mathrm{CI})$ of certainty (alpha $=0.05$ ). Since the total adult PLHIVs in the study area were less than 10,000 the population correction formula was applied and by taking $5 \%$ non-response rate the final sample size was determined as 384. A systematic random sampling technique was employed. Sampling interval $(\mathrm{k})$ was determined by dividing the total number of populations to the final sample size, which is 6 . The first PLHIVs was selected randomly by lottery method from the list 1-6 then every $6^{\text {th }}$ number from logo book order registration 2017 and the client was selected until the sample size were filled.

\section{Data collection and analysis:}

Face to face interview were conducted on socio demographic Variables, Weight, height and MUAC were measured by the data collectors and logo book was reviewed for the WHO stage and CD4 ${ }^{+}$. Data was analyzed and presented in table, graph and charts.

\section{Data quality assurance}

To ensure validity of the instrument, the draft questionnaire was submitted to the supervisor for comment regarding the relevance of each item. Training was given for the data collectors. During the data collection, supervision was done by principal investigator. Data cleaning up and cross-checking will be done before data processing and analysis.

\section{Ethical Consideration}

Ethical clearance and approval to conduct the study was obtained from Jimma University Ethical Review Board (JUIRB) and permission letter was secured in order to get support for the study from administrative body. The purpose of study was explained to the participants and they are told as participation was voluntarily, confidential and anonymity will be ensured throughout the execution. Finally, verbal and written consent was assured from the study subjects.

\section{Results}

Two hundred twenty-eight (67.5\%) were females and 109 (32.24\%) were males. The age range 25 to 29 includes the highest proportion that is $81(24 \%)$ patients and most $(89.31 \%)$ of the patients are from 20 to 49 years. Majority of the patients are Oromo by Ethnicity and Orthodox in religion. $78(23.14 \%), 59(17.5 \%)$ respectively and 46 $(13.6 \%)$ and $3(0.89 \%)$ of the patients are illiterate, read and write grade 1-8, grade 9-12, diploma and degree respectively.

One hundred seventy (50.44\%) of the patients are married and 56 $(16.6 \%)$ are single. Respondents on HAART 93 (27.5\%) develops opportunistic infection pneumonia followed by TB, skin infection and others $71(21 \%), 57(16.9 \%)$ and $116(34.42 \%)$ respectively (Table 1 and Figures 1 and 2).

\begin{tabular}{|c|c|c|c|}
\hline Characteristics & $\mathbf{n}$ & & $\%$ \\
\hline Sex & M & 109 & 32.34 \\
\hline & $\mathrm{F}$ & 228 & 67,6 \\
\hline & $15-19$ & 7 & 2.07 \\
\hline & $20-24$ & 33 & 9.79 \\
\hline & $25-29$ & 81 & 24.03 \\
\hline & $30-34$ & 74 & 21.95 \\
\hline Age & $35-39$ & 56 & 16,61 \\
\hline & $40-44$ & 38 & 11.27 \\
\hline & $45-49$ & 19 & 5.63 \\
\hline & $50-54$ & 14 & 4.15 \\
\hline & $>55$ & 15 & 4.45 \\
\hline & Orthodox & 161 & 47.7 \\
\hline Religion & Muslim & 94 & 27.28 \\
\hline & Protestant & 71 & 21.06 \\
\hline & Others & 11 & 3.26 \\
\hline
\end{tabular}


Citation: Gizaw AB, Gebremichael AE and Kebede DB (2018) Malnutrition and Associated Factors among Adult People Living with HIVIAIDS Receiving Antiretroviral Therapy at Organization for Social Service Health Development in Jimma Town Oromia Region South West Ethiopia. Gen Med (Los Angeles) 6: 315. doi:10.4172/2327-5146.1000315

Page 4 of 8

\begin{tabular}{|c|c|c|c|}
\hline \multirow{5}{*}{ Ethnicity } & Oromo & 135 & 40.05 \\
\hline & Amhara & 93 & 27.59 \\
\hline & Guraghe & 18 & 5.34 \\
\hline & Keffa & 59 & 17.5 \\
\hline & Others & 32 & 9.47 \\
\hline \multirow{6}{*}{ Educational level } & Illiterate & 78 & 23.14 \\
\hline & Read and write & 10 & 2.96 \\
\hline & Grade 1-8 & 120 & 35.6 \\
\hline & Grade 9-12 & 77 & 22.84 \\
\hline & Diploma & 49 & 14.54 \\
\hline & Degree & 3 & 0.89 \\
\hline \multirow{7}{*}{ Occupation } & Unemployed & 82 & 24.33 \\
\hline & Gov't employee & 53 & 15.72 \\
\hline & House wife & 71 & 21.06 \\
\hline & Merchant & 23 & 6.82 \\
\hline & Daily laborer & 77 & 22.84 \\
\hline & Student & 23 & 6.82 \\
\hline & Others & 8 & 2.37 \\
\hline \multirow{5}{*}{ Marital status } & Married & 170 & 50.44 \\
\hline & Single & 56 & 16.61 \\
\hline & Separated & 26 & 7.71 \\
\hline & Divorced & 39 & 11.57 \\
\hline & Widowed & 46 & 13.64 \\
\hline
\end{tabular}

Table 1: Sociodemographic characteristics of patients on HAART on the study of prevalence of malnutrition and associated factors at OSSHD clients 2017 G.C ( $=337)$.

Regarding monthly income of the study subjects $58.4 \%$ (197) respondents of on HAART at OSSHAD clients have got monthly income of $<1380$ birr which is low, $25.8 \%$ (87), $13.6 \%$ (46) and $2 \%(7)$ were get monthly income of 1380-6900, 6900-13800 and 13800-34500 respectively (Figure 3).

To identify the nutritional status of clients on HAART MUAC and BMI was taken for all patients and $260(77.15 \%)$ patients have MUAC $>21 \mathrm{~cm}, 69(20.47 \%)$ have MUAC $16-21 \mathrm{~cm}$ which is categorized under moderate malnutrition and $8(2 \%)$ have $M U A C<16$ $\mathrm{cm}$ which are categorized at severe malnutrition.

From the 337 patients included in the study BMI $>18.05$ were, $56.9 \%$, BMI $16-18.49$ were $26.7 \%$ and BMI of $<16$ were $16.3 \%$. Nearly half of the clients (153) on HAART at OSSHD were feed three times per day flowered by 149 feed two times per day and 30 respondents feed greater than three times (Tables 2-4 and Figure 3).

Table 3 shows immunologic status of study participants before and after the start of ART. Only $33.82 \%$ of the study subjects have CD4 count of 201-350 before initiation of ART but after the start of ART $74.87 \%$ of the study subjects achieved CD4 count of $>300$. Concerning the WHO clinical staging $8.6 \%$ of the participants were on stage I and $28.4 \%$ were on stage IV.

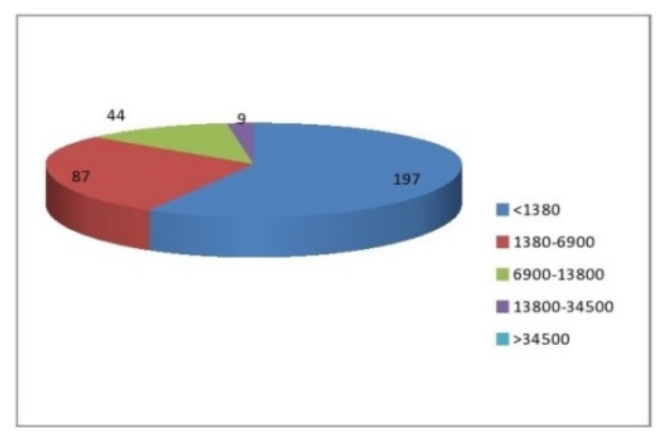

Figure 1: Distributions of monthly income of adult PLHIVs on HARRT on the study of prevalence of malnutrition and associated factors at OSSHAD clients in 2017 G.C. 
Citation: Gizaw AB, Gebremichael AE and Kebede DB (2018) Malnutrition and Associated Factors among Adult People Living with HIVIAIDS Receiving Antiretroviral Therapy at Organization for Social Service Health Development in Jimma Town Oromia Region South West Ethiopia. Gen Med (Los Angeles) 6: 315. doi:10.4172/2327-5146.1000315

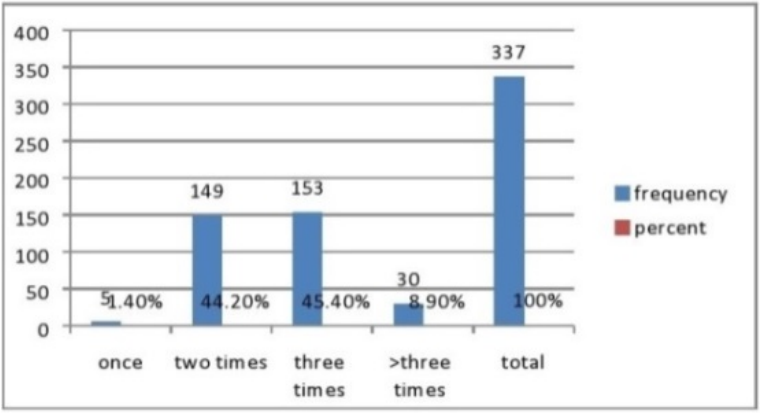

Figure 2: Distributions of daily feeding times of the adult PLHIVs on HAART on the study of prevalence of malnutrition and associated factors at OSSHD clients in 2017 G.C.

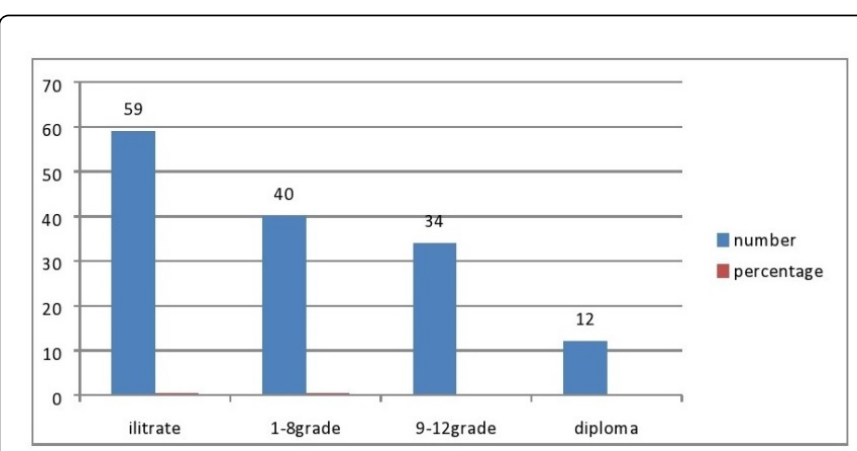

Figure 3: Distributions of malnourished adult PLHIVs in OSSHD clients on HAART by their educational status in 2017 G.C.

\begin{tabular}{|l|l|l|l|}
\hline Nutritional status measuring parameters & Category & $\mathbf{n}$ & \% \\
\hline \multirow{2}{*}{ BMI } & $<16$ & 55 & 16.32 \\
\cline { 2 - 4 } & $16-18.49$ & 90 & 26.70 \\
\cline { 2 - 4 } & $>18.5$ & 192 & 56.97 \\
\cline { 2 - 4 } MUAC (in cm) & Total & 8 & 100 \\
\hline & $<16$ & 69 & 2.37 \\
\hline BMI -Body mass index & $16-21$ & 260 & 20.47 \\
\hline MUAC-Mid upper arm circumference & $>21$ & 337 & 77.15 \\
\cline { 2 - 4 } & Total & - & 100 \\
\hline
\end{tabular}

Table 2: Nutritional status of patients on HAART on the study of prevalence of malnutrition and associated factors at OSSHD clients in 2017 G.C.

\begin{tabular}{|l|l|l|l|}
\hline $\begin{array}{l}\text { Immunologic status measuring } \\
\text { parameter }\end{array}$ & CD4 category & $\mathbf{n}$ & \% \\
\hline \hline $\mathrm{CD4}{ }^{+}$count at initiation of HAART & $<100$ & 96 & 28.48 \\
\hline $\mathrm{CD4}{ }^{+}$count after 6 months of HAART & $<200$ & 4 & 2.05 \\
\hline \hline & $200-300$ & 45 & 23.07 \\
\cline { 2 - 5 } & $>300$ & 146 & 74.87 \\
\hline
\end{tabular}

Educational status, marital status, WHO staging and income were significantly associated with malnutrition with $\mathrm{p}$ value of $<0.05$ (Table 5).

Table 3: Immunologic status of patients on HAART on the study of prevalence of malnutrition and associated factors at OSSHD clients at initiation and after 6 months of HAART, 2017 n=337. 
Citation: Gizaw AB, Gebremichael AE and Kebede DB (2018) Malnutrition and Associated Factors among Adult People Living with HIVIAIDS Receiving Antiretroviral Therapy at Organization for Social Service Health Development in Jimma Town Oromia Region South West Ethiopia. Gen Med (Los Angeles) 6: 315. doi:10.4172/2327-5146.1000315

Page 6 of 8

The overall prevalence of malnutrition among study participants receiving ART at OSSHD was $43 \%$. Moderate and severe malnutrition were observed on $90(26.7 \%)$ and $55(16.3 \%)$ participants, respectively. Malnutrition among illiterate patients was $17.5 \%$, but $3.56 \%$ (12), among those greater than grade 12 females (Figure 3). Levels of malnutrition were also different by marital status of the study subjects. Among 25 (7.4\%) of singles have malnutrition compared to $71(21 \%)$, $12(3.56 \%)$ and $16(4.74 \%)$ in those who are married, divorced and widowed respectively having evidence of malnutrition (Table 2).

\begin{tabular}{|l|l|l|}
\hline WHO stage & $\mathbf{n}$ & $\%$ \\
\hline Stage 1 & 29 & 8.60 \\
\hline Stage 2 & 75 & 22.20 \\
\hline Stage 3 & 137 & 40.60 \\
\hline Stage 4 & 96 & 28.40 \\
\hline
\end{tabular}

Table 4: WHO Stage of the study participants on the study of prevalence of malnutrition and associated factors at OSSHD among clients on HAART, 2017 ( $\mathrm{n}=337)$.

\begin{tabular}{|c|c|c|c|c|c|}
\hline \multirow{2}{*}{ Variables } & \multicolumn{2}{|c|}{ Nutritional status } & \multirow{2}{*}{$x^{2}$} & \multirow{2}{*}{ Df } & \multirow{2}{*}{$p$-value } \\
\hline & Malnourished & Normal nourished & & & \\
\hline Educational status & - & - & - & - & - \\
\hline Illiterate & 59 & 19 & 54.98 & 4 & $<0.001$ \\
\hline Read and write & 12 & 37 & - & - & - \\
\hline Grade1-8 & 40 & 80 & - & - & - \\
\hline Grade9-12 & 34 & 43 & - & - & - \\
\hline Diploma & 0 & 10 & - & - & - \\
\hline Degree & 0 & 3 & - & - & - \\
\hline Income & - & - & 21.6 & 3 & $<0.001$ \\
\hline$<1380$ & 69 & 128 & - & - & - \\
\hline $1380-6900$ & 51 & 36 & - & - & - \\
\hline $6900-13800$ & 17 & 27 & - & - & - \\
\hline $13800-34500$ & 8 & 1 & - & - & - \\
\hline WHO stage & - & - & 14.9 & 3 & $<0.001$ \\
\hline Stage 1 & 9 & 20 & - & - & - \\
\hline Stage 2 & 37 & 38 & - & - & - \\
\hline Stage 3 & 71 & 66 & - & - & - \\
\hline Stage 4 & 28 & 68 & - & - & - \\
\hline Marital status & - & - & - & - & - \\
\hline Married & 71 & 99 & 17.06 & 4 & $<0.01$ \\
\hline Single & 25 & 31 & - & - & - \\
\hline Separated & 21 & 5 & - & - & - \\
\hline Divorced & 12 & 27 & - & - & - \\
\hline Widowed & 16 & 30 & - & - & - \\
\hline
\end{tabular}

Table 5: Factors associated with prevalence of malnutrition on the study of prevalence of malnutrition and associated factors at OSSHD among clients on HAART, $2017(\mathrm{n}=337)$. 
Citation: Gizaw AB, Gebremichael AE and Kebede DB (2018) Malnutrition and Associated Factors among Adult People Living with HIVIAIDS Receiving Antiretroviral Therapy at Organization for Social Service Health Development in Jimma Town Oromia Region South West Ethiopia. Gen Med (Los Angeles) 6: 315. doi:10.4172/2327-5146.1000315

Page 7 of 8

\section{Discussion}

Weight loss is very common in HIV and AIDS patients and it has been correlated with disease progression and mortality. Level of malnutrition in this study was $43.02 \%$, this result is the line with study done in Thailand which is $41.3 \%$ [6] and also similar with a study done in Tigray Ethiopia which is $42.3 \%$ [30]. Higher than study conducted at Dilla (12.3\%), Gondar (25.5\%) and Bihar Dar [31-33]. The difference might be due to different socio-economic status, stages of HIV, and awareness levels among the study participants.

Slightly less than half (45.17\%) of females have evidence of malnutrition. This value is higher than the study done in Ethiopia which is $15.3 \%$ prevalence of malnutrition in HIV positive females and also higher than a study done in Sub-Saharan African countries which is $10.3 \%$ prevalence. The difference might be due to the difference in economic status of the clients in the study area [6].

Findings of this study indicated that there was a statistically significant association between educational status of respondents and malnutrition. The finding is consistent with studies at Kathmandu Valley, Nepal in which nutritional status and literacy level were identified as factors associated with malnutrition [34].

Demographic and Health Survey (DHS) on HIV positive females of reproductive age from sub-Saharan Africa countries including Ethiopia Showed wealth and educational status was also shown to have an inverse relation with prevalence and severity of HIV associated malnutrition [6].

In current study there is significant association was identified between the nutritional status at initiation of HAART and WHO clinical stage. Majority (77.8\%) of the patients who started HAART being in the WHO clinical stage four have moderate to severe malnutrition compared to $31.38 \%$ (43), $14 \%$ (15) and $4.82 \%$ (7) of those who started HAART being at stage III, II and I respectively $(p<0.001, d f=3)$. This finding is consistent with the study done in Uganda that showed HIV positive persons in WHO clinical stage four was characterized by sever wasting chronic fever and chronic diarrhea [35].

Higher risk of developing malnutrition in unemployed participants was found in this study. This finding is in line with other study where unemployment promotes poverty, which in turn limits the ability of individual to expend money for food consumption. The less likelihood of developing malnutrition among respondents in the middle and above monthly income economic status implies improved income level insures food security at household level. As it is confirmed by findings from previous study in Ethiopia, food insecurity is a significant problem for HIV positive people with low household income [36].

\section{Conclusion}

The results of this study provide data on the characteristics of nutritional status of HIV-positive adult patients in OSSHD clients and important associated factors. The study showed higher rate of malnutrition in HIV-AIDS patients receiving HAART at organization for social service health development (OSSHD) Jimma branches. Nearly half 145 (43.02\%) of the patients included in the study have evidence of malnutrition and associated with low monthly income, educational status and WHO staging at initiation of HAART. It has been learnt that malnutrition and its problems in HIV patients are complex and inter related; no single recipe exists as solution either. Hence, there is a prompt need to integrate nutritional care in the comprehensive continuum of HIV care. As well, it's needless to argue about improving household income through creating employment opportunities and engaging the needy unfortunates in amenable income generating activities will possibly alleviate these problems.

\section{Conflict of Interests}

All authors declared that they have no conflict of interests. Jimma University covered only the survey cost for this study and there is no any funding organization.

\section{Authors Contribution}

Aklilu Eshetu and Admasu Belay conceived and designed the protocol. Additionally Aklilu Eshetu performed the data collection. Admasu Belay and Dagmawit Birhanu contributed on data analysis, and checked the draft. Dagmawit Birhanu prepared manuscript. Admasu Belay approved it. Aklilu Eshetu and Admasu Belay contributed equally. All authors read and approved the final paper.

\section{Acknowledgement}

We would like to thank the organization for social service health development (OSSHD) Jimma branches staffs for all the help and support given for us during the data collection period. We also thank Jimma university institute of health for permitting us to conduct this study. Last, but not least we would like to acknowledge data collectors.

\section{References}

1. http://www.who.int/gho/en/ WHO (2018) Global Health Observatory data date accessed 24/6/2018

2. Ethiopian public health institute federal ministry of health (2014) HIV related estimates and projections for Ethiopia. 15-18.

3. Errayya D, Kumari PR, Sunita S, Lakshmi GV, Naidu SA, et al. (2014) A study on nutritional status and micronutrient deficiencies among primary school children. 20-23.

4. https://odihpn.org/magazine/\%C2\%91new-variant-famine $\% \mathrm{C} 2 \% 92$ revisited-chronic-vulnerability-in-rural-africa/

5. FAO/UN (2005) the state of food insecurity in the world: Eradicating world hunger-Key to achieving the MDGS, Rome Italy UN/ FAO 1-10.

6. https://www.hiv.gov/hiv-basics/overview/data-and-trends/globalstatistics

7. http://www.who.int/mediacentre/news/releases/2013/ new_hiv_recommendations_20130630/en/

8. http://www.who.int/hiv/pub/guidelines/en/

9. Cihla T, Fordyce M (2016) Current status and prospects of HIV treatment overlay panel 4-13. 
Citation: Gizaw AB, Gebremichael AE and Kebede DB (2018) Malnutrition and Associated Factors among Adult People Living with HIVIAIDS Receiving Antiretroviral Therapy at Organization for Social Service Health Development in Jimma Town Oromia Region South West Ethiopia. Gen Med (Los Angeles) 6: 315. doi:10.4172/2327-5146.1000315

Page 8 of 8

10. Moges NA, Kassa GM (2014) Prevalence of opportunistic infections and associated factors among HIV positive patients taking anti-retrovira therapy in debremarkos referral hospital, Northwest Ethiopia. 1-23.

11. Chaisson RE, Gallant JE, Keruly JC, Moore RD (1998) Impact of opportunistic disease on survival in patients with HIV infection AIDS. 12: $29-33$

12. Lajoie BMR, Drouin O, Bartlett G, Nguyen Q, Low A, et al. (2016) Incidence and prevalence of opportunistic and other infections and the impact of antiretroviral therapy among HIV-infected children in low and middle income countries: A systematic review and meta-analysis.

13. pau ak, pharm d, george jm (2014) antiretroviral therapy: current drugs.

14. Sicotte M, Langlois EV, Aho J, Ziegler D, Zunzunegui MV, et al. (2014) Association between nutritional status and the immune response in HIV + patients under HAART.

15. Salomon J, Truchis PD, Melchior JC (2002) Nutrition and HIV infection, wasting syndrome and malnutrition 112-113.

16. Shevitz AH, Knox TA, Spiegelman D, Roubenoff R, Gorbach SL, et al. (1999) Elevated resting energy expenditure among HIV-seropositive persons receiving highly active antiretroviral therapy. AIDS 13: 13511357.

17. Wakeham K, Harding R, Bamukama ND, Levin J, Kissa J, et al. (2010) Symptom burden in HIV-infected adults at time of HIV diagnosis in rural Uganda. J Palliat Med 13: 375-380.

18. Ivers LC, Cullen KA, Freedberg KA, Block S, Coates J, et al. (2009) Webb p: HIV/AIDS under nutrition and food insecurity. Clin Infect Dis 49 1096-1102.

19. Nishijima T, Komatsu H, Gatanaga H, Aoki T, Watanabe K, et al. (2011) Impact of small body weight on tenofovir associated renal dysfunction in HIV infected patients 6: e22661.

20. Sanne I, Mommeja MH, Hinkle J, Bartlett JA, Lederman MM, et al. (2001) Severe hepatotoxicity 191: 825-829.

21. Subbaraman R, Chaguturu SK, Mayer KH, Flanigan TP, Kumarasamy N, et al. (2007) Adverse effects of highly active antiretroviral therapy in developing countries. Clin Infect Dis 45: 1093-1101.

22. Kiertiburanakul S, Sungkanuparph S, Charoenyingwattana A, Mahasirimongkol S, Sura T, et al. (2008) Risk factors for nevirapine associated rash among HIV infected patients with low CD4 cell counts in resource limited settings. Curr HIV Res 6: 65-69.

23. Lee JH, Suh OK, Lee MG (2004) Pharmacokinetic changes in drugs during protein calorie malnutrition: Correlation between drug metabolism and hepatic microsomal cytochrome 27: 693-712
24. Berhe N, Tegabu D, Alemayehu M (2013) Effect of nutritional factors on adherence to antiretroviral therapy among HIV-infected adults: A case control study in Northern Ethiopia. BMC Infect Dis 13: 233

25. Kotlermd P (1997) Malnutrition in HIV infection 393-415.

26. Winter JE, MacInnis RJ, Wattanapenpaiboon N, Nowson CA (2014) A meta analysis BMI and all cause mortality in older adults.

27. Takarinda KC, Mutasa AT, Madzima B (2017) Malnutrition status and associated factors among HIV positive patients enrolled in ART clinics in Zimbabwe.

28. Daniel M, Mazengia F, Birhanu D (2013) Nutritional status and associated factors among adult HIV/AIDS clients in Felege Hiwot Referral hospital, Bahirdar, Ethiopia. Science 124-131.

29. Hailemariam S, Bune GT, Ayele HT (2013) Malnutrition: Prevalence and its associated factors in people living with HIV/AIDS, in Dilla university referral hospital. Arch Public Health 71-113

30. WHO (2004) Physical status: The use and interpretation of anthropometry: In report of a WHO expert Committee. vol. 854th ed. Edited by series WTR. Geneva.

31. Hadgu TH, Worku W, Tetemke D, Berhe H (2013) Under nutrition among HIV positive women in Humera hospital, Tigray, Ethiopia 13-43.

32. Unge C, Sodergard B, Marrone G, Thorson A, Lukhwaro A, et al. (2010) Long term adherence to antiretroviral treatment and program drop out in a high risk urban setting in sub-saharan Africa.

33. Rawat R, Kadiyala S, McNamara EP (2010) The impact of food assistance on weight gain and disease progression among HIV-infected individuals accessing AIDS care and treatment services in Uganda 362-372.

34. Tiyou A, Belachew T, Alemseged F, Biadgilign S (2012) Food insecurity and associated factors among HIV infected individuals receiving highly active antiretroviral therapy in South West Ethiopia.

35. Rawat R, Kadiyala S, McNamara PE (2012) The impact of food assistance on weight gain and disease progression among HIV-infected individuals accessing AIDS care and treatment services in Uganda. BMC Public Health 10: 316.

36. Tiyou A, Belachew T, Alemseged F, Biadgilign S (2012) Food insecurity and associated factors among HIV-infected individuals receiving highly active antiretroviral therapy in Jimma zone Southwest Ethiopia. Nutr J 11: 51. 